however, support our idea that the carbohaemoglobin level is actually the factor affecting the pulse oximeter readings.

Lastly, we must mention that our study provides the first observation that carbon dioxide arterial tension can have an influence on the arterial oxygen saturation measured by pulse oximery reading. Future studies should confirm this finding and investigate the mechanisms responsible for this effect.

\section{Muñoz ${ }^{* \star \oplus}$, F. Torres ${ }^{+}$and G. Sampol*ף}

*Servei de Pneumologia, Hospital Universitari Vall d'Hebron, \#Dept de Biología Cel-lular, de Fisiologia i d'Immunologia, Universitat Autònoma de Barcelona (UAB), ${ }^{+}$Laboratorio de Bioestadística i Epidemiología, UAB, Servei de Farmacologia Clínica, Institut d'Investigacions Biomèdiques August Pi i Sunyer, (Hospital Clínic), Barcelona, and "Centro de
Investigación Biomédica en Red de Enfermedades Respiratorias (CIBER) de Enfermedades Respiratorias (Ciberes), Spain.

\section{STATEMENT OF INTEREST}

None declared.

\section{REFERENCES}

1 Muñoz X, Torres F, Sampol G, Rios J, Martí S, Escrich E. Accuracy and reliability of pulse oximetry at different arterial carbon dioxide pressure levels. Eur Respir J 2008; 32: 1053-1059.

DOI: 10.1183/09031936.00127908

\title{
Diagnostic utility of a novel thin bronchoscope
}

\section{To the Editors:}

In a recent issue of the European Respiratory Journal (ERJ), OKI et al. [1] evaluated the diagnostic utility of a novel thin bronchoscope with a $1.7-\mathrm{mm}$ working channel for peripheral pulmonary lesions. We have a few comments we would like to make about this article.

First, all bronchoscopists know that bleeding occurs to some degree in virtually all transbronchial lung biopsy (TBLB) procedures and, in some cases, can be substantial. Further, the bronchoscopist has limited options available to manage excessive bleeding through the flexible bronchoscope. In fact, the suction channel of the typical bronchoscope is only $2 \mathrm{~mm}$ in diameter, and the volume of blood that can be suctioned through the channel is therefore limited. The use of a thin bronchoscope with a $1.7-\mathrm{mm}$ working channel may not be adequate to control a possible bleeding. For these reasons, we doubt that the use of this bronchoscope is completely safe for TBLBs of peripheral pulmonary lesions.

Secondly, it has been shown that large forceps are expected to result in larger specimens and to improve the diagnostic yield (although mainly in non-neoplastic disease). In a study by CURLEY et al. [2], it was reported that larger TBLBs were more likely to contain diagnostic tissue, while LOUBE et al. [3] prospectively compared the diagnostic yield of TBLBs using large and small forceps (cup size $3 \times 2 \times 0.9$ versus $2 \times 1.5 \times 0.6 \mathrm{~mm}$, respectively), proving that large forceps obtained significantly more tissue than small forceps. Therefore, the use of small biopsy forceps for the $1.7-\mathrm{mm}$ working channel could significantly reduce the diagnostic yield of TBLB.

We believe that the best approach to peripheral pulmonary lesions, particularly when they are $\leqslant 2 \mathrm{~cm}$, is still endobronchial ultrasound-guided transbronchial lung biopsy [4], which has proved a safe and very effective method for peripheral pulmonary lesions that cannot be visualised with fluoroscopy, as was indeed correctly reported by OKI et al. [1]. The procedure may increase the yield of endoscopic biopsy in patients with these nodules [5] and there is no reduction in the control of possible bleeding related to procedure.

\section{G.L. Casoni and V. Poletti}

Thoracic Dept, G.B. Morgagni Hospital, Forlì, Italy.

\section{STATEMENT OF INTEREST}

None declared.

\section{REFERENCES}

1 Oki M, Saka H, Kitagawa C, et al. Novel thin bronchoscope with a 1.7-mm working channel for peripheral pulmonary lesions. Eur Respir J 2008; 32: 465-471.

2 Curley FJ, Johal JS, Burke ME, Fraire AE. Transbronchial lung biopsy: can specimen quality be predicted at the time of biopsy? Chest 1998; 113: 1037-1041.

3 Loube DI, Johnson JE, Wiener D, Anders GT, Blanton HM, Hayes JA. The effect of forceps size on the adequacy of specimens obtained by transbronchial biopsy. Am Rev Respir Dis 1993; 148: 1411-1413.

4 Paone G, Nicastri E, Lucantoni G, et al. Endobronchial ultrasound-driven biopsy in the diagnosis of peripheral lung lesions. Chest 2005; 128: 3551-3557.

5 Herth FJ, Eberhardt R, Becker HD, Ernst A. Endobronchial ultrasound-guided transbronchial lung biopsy in fluoroscopically invisible solitary pulmonary nodules. Chest 2006; 129: 147-150. 